\title{
Building the Case for Nurses' Continuous Professional Development in Ethiopia: A Qualitative Study of the Sick Kids-Ethiopia Paediatrics Perioperative Nursing Training Program
}

\author{
Leyouget Abebe $^{1 *}$, Amy Bender ${ }^{2}$, Richard Pittini ${ }^{3}$
}

\author{
OPEN ACCESS \\ Citation: Leyouget Abebe, Amy Bender, \\ Richard Pittini. Building the Case for \\ Nurses' Continuous Professional \\ Development in Ethiopia: A Qualitative \\ Study of the SickKids-Ethiopia \\ Paediatrics Perioperative Nursing \\ Training Program. Ethiop J Health \\ Sci.2018;28 (5):607. \\ doi:http://dx.doi.org/10.4314/ejhs.v28i5.12 \\ Received: January 12, 2017 \\ Accepted: January 16, 2017 \\ Published: September 1, 2018 \\ Copyright: (C) 2018 Leyouget Abebe, et \\ al. This is an open access article \\ distributed under the terms of the \\ Creative Commons Attribution License, \\ which permits unrestricted use, \\ distribution, and reproduction in any \\ medium, provided the original author and \\ source are credited. \\ Funding: Nil \\ Competing Interests: The authors \\ declare that this manuscript was approved \\ by all authors in its form and that no \\ competing interest exists. \\ Affiliation and Correspondence: \\ ${ }^{1}$ St. Paul's Hospital Millennium \\ Medical College, Addis Ababa, \\ Ethiopia \\ ${ }^{2}$ Lawrence S. Bloomberg Faculty of \\ Nursing, University of Toronto \\ ${ }^{3}$ Undergraduate Medical Education, \\ University of Toronto \\ *Email: liyu.abebe@sphmmc.edu.et
}

ABSTRACT

BACKGROUND: This study describes the in-service training experience of perioperative nurses from the SickKids-Ethiopia Paediatrics Perioperative Nursing Training Program in Addis Ababa, Ethiopia. The study emphasizes specifically how nurses applied the knowledge and skills gained from the Paediatrics Perioperative Nursing Training program in their subsequent practice and consider the situational factors that facilitated or hindered implementing these new knowledge and skills.

METHODS: The first author led qualitative in-depth interviews with nine perioperative nurses who participated in training in September 2016, and systematically developed descriptive codes and themes to analyze the data.

RESULTS: The authors found that participants experienced improved knowledge, skills, confidence, and job retention related to perioperative nursing practice after participating in Paediatrics Perioperative Nursing Training. Participants also stressed key challenges including lack of access to ongoing perioperative inservice training and problematic staffing policies that impact perioperative nurses' ability to fully utilize and share new knowledge gained during CPD training.

CONCLUSION: The findings highlighted the value of specialized perioperative CPD training for Ethiopian nurses, yet also pointed to multidimensional challenges for knowledge translation and sustainability of best practices. The authors offer recommendations for individual and institutional strategies to address some of them. KEYWORDS: Continuous professional development, Perioperative nursing, Resource limited setting

\section{INTRODUCTION}

In nursing, continuous professional development programs (CPD) have been conceptualized as formal learning activities by which nurses are able to remain up-to-date with advances in knowledge, skills, technology and practice to provide quality health service, improve professional and personal growth, and job satisfaction (1). Such activities vary widely and can include in-service trainings, workshops, lectures and presentations (2). Studies conducted to evaluate the effectiveness of CPD on nursing practice have shown 
that in addition to improving nurses' knowledge and skills, several such programs contributed to service improvements, staff retention, role expansion, and a personal sense of satisfaction (3)(4). However, in low and middle income countries (LMICs) the scenario is different. There is some evidence of improvements in increasing the short term knowledge and attitudes of nurses in these contexts; however, most programs failed to significantly improve clinical practice. A notable reason for this is the majority of the programs were developed based on high income countries' (HICs) standards and resource-rich contexts, yet carried out with resource limitations and program sustainability issues (5)(6).

In Ethiopia, the Federal Ministry of Health (FMOH) acknowledges gaps in CPD for all health professionals in its 2015-2020 health sector transformation plan, identified that some are not need based or well planned and lack documentation and evaluation (7).

In this paper, we present a descriptive qualitative study in an effort to contribute to this fledgling area of global interprofessional health education. The case presented is that of a CPD training program for perioperative nurses in Addis Ababa. Although nursing is the focus, the results have implications for all health professions to consider, including system administrators. After an overview of the program, we describe the study methods and main findings, and conclude with comments regarding some implications of this study for CPD in Ethiopian nursing.

According to the American-based Association of Registered Nurses (AORN), perioperative nursing practice refers to the provision of services across the surgical continuum of preoperative, intraoperative and postoperative nursing care (8) Although limited; research that describes the impact of nurses in surgical patient care in Ethiopia reports a significant gap in addressing perioperative education needs for practising nurses. According to Friends of African Nursing (FoAN), a UKbased charity (9) report, in most African countries perioperative education is limited or not available. In addition, nurses work in settings that lack proper infrastructure, functional equipment and important items such as gloves, dressings and scrub solutions. A volunteer for FoAN who provide two days training at three hospitals in different regions of Ethiopia noted that perioperative nursing practice in the country was poor (10). According to the report, pre and postoperative care were neglected; there was low motivation and ambition of nursing staff to adapt new experiences, unsafe sharps practices, and poor cleanliness; and nursing leadership and staff development were clearly areas that needed to be developed.

The SickKids-Ethiopia Paediatrics Perioperative Nursing Training (PONT) Program: The Pediatric Perioperative Nursing Training (PONT) certificate program was a joint initiative of the Hospital for Sick Children (SickKids) in Toronto Canada, the Surgical Society of Ethiopia, and Addis Ababa University's Department of Nursing and Midwifery. The curriculum was guided by the Association of Perioperative Registered Nurses (AORN) standards (8). Through the development and design of a contextually relevant certificate course for perioperative nurses, the expected impact of the program was to train 60 paediatric perioperative nurses in hospitals and clinical settings, and to sustain the PONT program by producing dedicated co-trainers who would continue the course in Ethiopia beyond the initial training (11). Trainees were recruited from sites representing both public and private sector facilities from across five regions in Ethiopia who were working in the perioperative setting and nursing teaching institutions. Atotal of 65 nurses completed the training in the period April 2014 March 2015 in three rounds.

The training program is a four week block course. Course content included perioperative nursing roles, patient safety, sterilization, nursing care related to anaesthesia, the paediatric patient, operating room equipment, and clinical leadership.

Classroom sessions were complemented with demonstration, videos, case studies, and simulation-based skills training. 
Trainees had six days of clinical practical attachments in the operating room where they were coached by course facilitators.

\section{METHODS}

Ethical approval was obtained from Addis Ababa University to conduct the study. A total of nine nurses $(\mathrm{N}=9)$ who completed the PONT program were selected from seven public hospitals to participate in this study, These nine nurses were selected from a total of 65 by using the following criteria:

1. Have completed the PONT program

2. Currently working in public hospital

3. Have worked in the Operating theatre Room

To ensure maximum variation of experiences, at least one participant was interviewed from each of the public hospitals represented in the training.

Four men and five women participated, and their age ranged from 27 to 53. All participants were Bsc level nurses; eight in General Nursing and one in Operation Theatre Nursing. The length of the time in practice spanned 6-32 years, and in perioperative nursing specifically, the range was 6-19 years.

Semi-structured interviews were conducted using an interview guide by hired interviewer. The length of interviews ranged from 25 to 37 minutes. All interviews were conducted in Amharic and transcribed by the first author, with corresponding numerical codes to ensure participant anonymity. The first author also translated all transcripts from Amharic into English.

We analysed the data inductively using a systematic process of coding and the development of themes (12). This began with close reading of each transcript repeatedly to make sense of the ideas and identify key concepts being expressed. These concepts were then categorized using a short list of universal codes developed from the literature review. As new codes emerged in the data, they were added to list. Theoretical codes that were not present in the data were removed. After several updates of the list, codes were grouped into categories and from these categories general themes were identified that most accurately and completely reflected participants experiences.

\section{RESULTS}

The three key interrelated themes are detailed below. They include 1) using and sharing new knowledge, skills and confidence gained from PONT; 2) the availability of appropriate accessible perioperative in-service training; and 3) sustainability of changes, both personal and programmatic. Facilitators and barriers of each theme are embedded throughout the section.

Using and sharing new knowledge, skills and confidence: All participants acknowledged that PONT helped them to acquire new knowledge and skills, and to refresh what they knew before. Eight of the nine participants reported that the PONT training was the first time they heard of the stroke and time methods of scrubbing. Two participants revealed that most of the staffs including themselves did not give due emphasis to decontamination as they believed that the postoperative antibiotics prescribed for patients were enough to prevent postoperative infection. As one participant stated, "people in the OR do scrubbing in any way they want -I prefer to call it now hand washing and I used to scrub like them" (P4). The majority of participants said they stopped previous routine hand hygiene practices, and that they now always use the stroke or time scrubbing method. This relates to having developed new awareness and insight regarding consistent ethical practices in the surgical setting.

All participants described the training as motivating for them to correct bad practices and adopt behaviours that bring change to their work areas. Most of them said they attempted to make the following changes in their workplaces: to initiate the use of instrument counting sheets and implementing the WHO surgical safety checklists, to educate their colleagues on proper scrubbing techniques, gowning and gloving, and preoperative patient assessments and hand-over practices in postoperative care.

As five participants (P1, P3, P5, P8, and P9) shared, before PONT training, surgical safety check lists were not implemented in their hospital; they were not recording instruments used for surgery. After returning from receiving the

DOI: http://dx.doi.org/10.4314/ejhs.v28i5.12 
training they took the initiative to prepare a count sheet and duplicate the checklists.

All participants said they tried to share the new knowledge and skills obtained from participating in the PONT program with their colleagues, through informal sharing, demonstration and teaching of new staffs. In three government hospitals participants were able to organize orientation training programs more formally for all nurses who work in the OR. Although all the participants said they tried to train their colleagues who did not have the opportunity for training, some were not open to the teaching, as explained by one participant:

"we were only four nurses who took the training among more than 40 nurses work in the operating theatre, sometimes we faced some resistance from our colleagues specially from senior ones, as they thought they are expert enough in the field." (P2)

Some participants, in addition to teaching colleagues, taught and mentored nursing and medical students.

Availability of accessible training: With the exception of one nurse who attended a three-day training on infection prevention, all participants reported that they had not received any perioperative in-service training prior to participating in PONT. Similarly since completing the PONT program, only one participant reported attending a related CPD program in Europe. Given this, they were asked about the ways in which they gained and maintained the necessary knowledge and skills for working in the perioperative nursing environment. Everyone said they learned from senior staff, who themselves likely did not receive any specialized perioperative nursing training in the ORs where they worked. Eight of the nine participants said they learned about it in courses in nursing school; however, that this was not enough to prepare them appropriately for actual practice. This was expressed by one participant as follows:

"I remember the first time I was assigned to work in OR. Even if I had taken a two credit hour course on perioperative nursing care when I was a student nurse, it was not indepth and I had no opportunity even to visit
OR. The environment, the procedures were new to me. Even I couldn't perform simple tasks like opening and closure of artery forceps. "(P5)

Another participant highlighted by saying that "it is common to see gap in knowledge and skills on newly assigned staffs which directly affect the wellbeing of the patient" (P2). She shared the examples of new nurses routinely touching the sterile field bare hands; and cases in which a piece of grafted skin was removed during a dressing change. It was also highlighted that such limitations also have an effect on confidence, both in terms of nurses' own and that of other professionals. As one participant explained,

"Lack of knowledge and skills to OR practice is always a cause for frustrations and conflict with surgeons. Even there are some nurses who decides not to work in OR as they feel lack of confidence of scrubbing for some procedures." (P6)

The concern for having access to appropriate and thorough education in this highly specialized area of nursing was clear across all interviews. P1 stated, "Such kinds of training refresh and motivate in bringing change as they are focused on specific area which is related to the actual job". Similarly, P7 pointed out that "in-service trainings are important as they are focused, can be easily retained, and the materials...serve as future reference". These quotes highlight that training not only expands knowledge and skills, and provides valuable reference resources, but also plays a role in shifting attitudes toward the work itself, serving as a motivation for improving care.

Sustainability of changes: In terms of being able to sustain changes in practice that were a result of PONT, there were benefits and challenges for participants themselves as well as for perioperative service delivery. Some participants shared that the training helped to improve their careers. For example, one participant was able to go to a Scandinavian country as part of experience sharing visit, and explained that the PONT program “... helped me not to be new for most of the operating room practices and I was confident

DOI: http://dx.doi.org/10.4314/ejhs.v28i5.12 
to perform in the standard way"(P5). Another said the PONT certificate helped him to secure an instructor job in the Operating Theatre Nursing department (P1). And, for the majority of participants, the certificate facilitated remaining on the OR staff team during the 'annual rotation', a common policy of government hospitals that reassigns all nurses to work in different departments every one or two years.

For some participants with administrative positions has enabled them bring the desired changes. For example, those participants who were OR managers said their position allowed access to resources such as photocopying of checklists and count sheets, and materials for the preparation of properly sized patient drapes and gowns, thereby reducing the use of worn-out clothes. One manager used this position to arrange staff training:

"As the Operating director surgeons were supportive in my idea of providing training for the staffs, I had no problem organizing orientation training to the staffs; besides we have good team spirit in the OR and all of the staffs were committed to learn from us."( $(\mathrm{P} 8)$

Their power also allowed them to insist on current hospital reform guidelines being followed to support the implementation of the WHO checklist, as P8 described in the following quote:

"When we submit monthly surgical activity report to the Ministry of Health implementing the WHO checklists becomes one of the parameters that assess the safe surgical services we provided".

Sustaining change was also constrained. Although all participants were doing their best with the resources they had, shortage of materials and equipment such as proper types of prepping solutions, draping materials, and surgical instruments were identified as the major challenge hindering the implementation of the newly acquired knowledge and skills in practice. For example, P8 and P4 explained that they facilitated the preparation of surgical checklists and count sheets but after some time this was discontinued due to shortage of paper for printing.

Sustaining changes in practice was also affected by personal motivation to work in the area. Some participants said even if they like working in OR, remuneration in the form of 'risk allowance' was not aligned with other health professionals' pay. As described by one participant, "even if all staffs exposed to the same risks in the OR, the huge difference in the risk allowance payment paid for different health professionals decreases nurses motivation to work in OR and decreases team spirit among professionals". (P7)

According to most of the participants, Annual rotation policy that currently requires nurses to be reassigned to work in different departments every one or two years is the major concern for sustaining practice changes. This includes the OR. The objective of this policy is to ensure that all staffs are given the opportunity to work and learn in all clinical areas. Yet the majority of participants saw it as negatively affecting perioperative nursing care services. The following quotes highlight the issues that arise from the policy:

"Every staff is expected to be rotated to work in different departments once they serve maximum of two years unless they have more than three months specialty training in that area. Interest and years of clinical area are not taken into account." (P2)

"OR is not like other departments that one can easily learn how to work. The cases how to work with instruments, where instruments located take time to learn. It will take months for some staffs to learn effectively work in the area. When they become efficient their rotation period ends and they will be transferred to work to other area." (P9)

"Rotation brings extra work load on the existing staff as it requires training of the new comers. . . Despite my interest, long OR service and the training I have, I was assigned to another department and would have gone lest the request of head of the OR". (P7)

"The surgeons even complained to the hospital administrators not to rotate those experienced nurses, but the administrators believed that all graduate nurses should be competent to all clinical practices. But the reality is not like that."(P3) 
Finally, all participants suggested that PONT or similar training programs should be available for all perioperative staff and the time allocated for the training to be increased. Some participants also suggested that education in perioperative nursing should be made available at the Master's degree level, in order to contribute to nurses' professional growth and retention in their professional area.

\section{DISCUSSION}

Despite the lack of access to CPD programs in perioperative nursing in Ethiopia, participants valued the impact that PONT had on improving knowledge and skills. This has been reported in previous studies, which highlighted that certification improved nurses' personal and professional growth (3) (13) (14) (15). In this study, shortages of resources, manpower, and insufficient materials and equipment were identified as major factors in hampering the adaptation of new knowledge into practice. This is similar to other limited resource settings, where knowledge translation has been found to falter due to lack of proper infrastructure and non-functional equipment (5) (6) (9).

Advanced practice nursing, including speciality nursing programs, has been developing globally to optimize the quality of patient care provision (17). Empowering generalist health care provider through education and in-service trainings is a cost-effective strategy to improve the quality of health care services in resource-limited settings (19). This study also reflects the importance of providing specialty training for perioperative nurses to ensure the delivery of quality patient care and increase nurses' motivation to stay in this important area of profession.

In conclusion, while we have sought to advance the limited research on CPD for nurses in Ethiopia, we recognize this was a small study with some limitations. Although PONT was offered to nurses working in private and public hospitals around the country, only nurses working in the Operating Room in Addis Ababa public hospitals were included.
PONT is one example of how CPD programs have the power to instil motivation for bringing about positive change in patient care and retention of competent specialized staff. However, the challenges of doing so, expressed by this study's participants, also highlight how lack of resources and institutional rotation of trained nurses are problematic for sustaining such changes.

We offer the following recommendations from our findings. First, in the global era of subspecialization in medicine, and competency-based curricula in all of healthcare, building educational leadership in speciality areas will help in staff retention (17). For perioperative nursing specifically, this study highlights the need to shift from a generalist view of the nursing role to one of specialization. Second, Health care and nursing education institutions rethinking policies of rotating speciality trained nurses across different departments. It is also highlights that the creation or a robust CPD program for perioperative is on area in urgent need of attention. This may happen through the Ethiopian Ministry of Health and Health Care Associations, who have the authority to conduct appropriate systematic needs assessments, and to implement (CPD) courses through the necessary partnership and networking.

DOI: http://dx.doi.org/10.4314/ejhs.v28i5.12 


\section{ACKNOWLEDGEMENTS}

We are grateful to the PONT trainees who participated in this study. We would also like to thank Stephanie de Young, RN, MSc (Nursing Manager, Centre for Global Child Health, SickKids), for her leadership in the program, and taking time to share documents, read the proposal and provide feedback.

\section{REFERENCES}

1. Gallagher L. Continuing education in nursing: a concept analysis. Nurse Educ Today, 2007; 27(5):466-473.

2. Barriball KL, While AE, Norman IJ. Continuing professional education for qualified nurses: a review of the literature. $J$ of Adv Nurs, 1992; 17(9):1129-1140.

3. Fitzpatrick JJ, Campo TM, Graham G, Lavandero R. Certification, empowerment, and intent to leave current position and the profession among critical care nurses. $\mathrm{Am} \mathrm{J}$ Crit Care. 2010.(19)3:218-226. Doi:10.4037/ajcc2010442

4. Gould D, Berridge EJ, Kelly D. The National Health Service Knowledge and Skills Framework and its implementations for continuing professional development in nursing. Nurse Educ Today. 2007. ;27(1): 2634. doi:10.1016/j.nedt.2006.02.006

5. Kawaguchi A, Mori R.The In-Service Training for Health Professionals to Improve Care of the Seriously Ill Newborn or Child in Low- and Middle-Income Countries.Geneva:Switzerland. 2010.

6. Uwajeneza P. Continues Professional Development in Rwanda: The Experience of Midwives who Participated in the Advanced Life Support in Obstetrics (ALSO) Educational Program. (2015)

7. Federal Democratic Republic of Ethiopia Ministry of Health: Health Sector Transformation Plan 2015/16-2019/20.
8. Spruce L, Burlingame B, Denholm B, Ogg M, Vanwicklin SA. Association of Perioperative Registered Nurses AORN. Perioperative standards and recommended practices for Inpatients and Ambulatory Settings; AORN Publication Department. 2013.

9. Evans C. Operation Africa Nursing. Nurs Stand 2009; 23(27)62-3.

10. Knight, M. Friends of African Nursing (CANADA). ORNAC J. 2011; 29(1): 16.

11. Ethiopia-SickKids Perioperative Nursing Training Programme. Available at file:///C:review/Ethiopia-

SickKidsPerioperativeNursingTraining Programme.html. Accessed September 10, 2016.

12. Yin RK. Case Study Research: Design and Methods. Thousand Oaks: Sage; 2003.

13. Schroeter K, Byrne MM, Klink KA, BeierM, McAndrew NS. The impact of certification on certified perioperative nurses: a qualitative descriptive survey. ORNAC J., 2012; 30(3): 34-46.

14. Hines S, Chang A, Ramis MA, Pike S. Effectiveness of nurse-led preoperative assessment services for elective surgery: a systematic review. JBI Database f Systematic Reviews and Implementation Reports. 2010. 8(15):621-660.

15. Stevens B, Donkor ES, Goka BQ et al. Impact and sustainability of an accredited pediatric nursing training program in Ghana. $J$ Nurs Educ Pract. 2014; 4(12):142-154.

16. Uwajeneza P. Continues Professional Development in Rwanda: The Experience of Midwives who participated in the Advanced Life Support in Obstetrics (ALSO) Educational Program. Electronic Thesis and Dissertation Repository 2015; Paper 2810. http://ir.lib.uwo.ca/etd/2810

17. Sheer B, Wong FK. The development of advanced nursing practice globally. $J$ Nurs Scholarsh, 2008;40(3):204-211. 
18. Cancedda C, Farmer PE, Kyamanywa P, et al. Enhancing formal educational and in-service training programs in rural Rwanda: A Partnership among the public sector, a nongovernmental Organization, and academia. Acad Med. 2014; 89(8):1117-1124.

19. Asegid A, Belachew T, Yimam E. factors influencing job satisfaction and anticipated turnover among Nurses in Sidama zone public health facilities, South Ethiopia. Nurs Res and Pract, 2014;89(8):1117-1124.

20. O Malley G, Perdue T, Petracca F. A frame work for outcome-level evaluation of inservice training of health care workers. Humn Resour Health.

DOI: http://dx.doi.org/10.4314/ejhs.v28i5.12 